Document downloaded from:

http://hdl.handle.net/10251/55123

This paper must be cited as:

García Taengua, EJ.; Martí Vargas, JR.; Serna Ros, P. (2014). Bond of Reinforcement in Concrete Applied to Concrete Quality Control: The Bottle Bond Test. Strain. 50(1):57-67. doi:10.1111/str.12067.

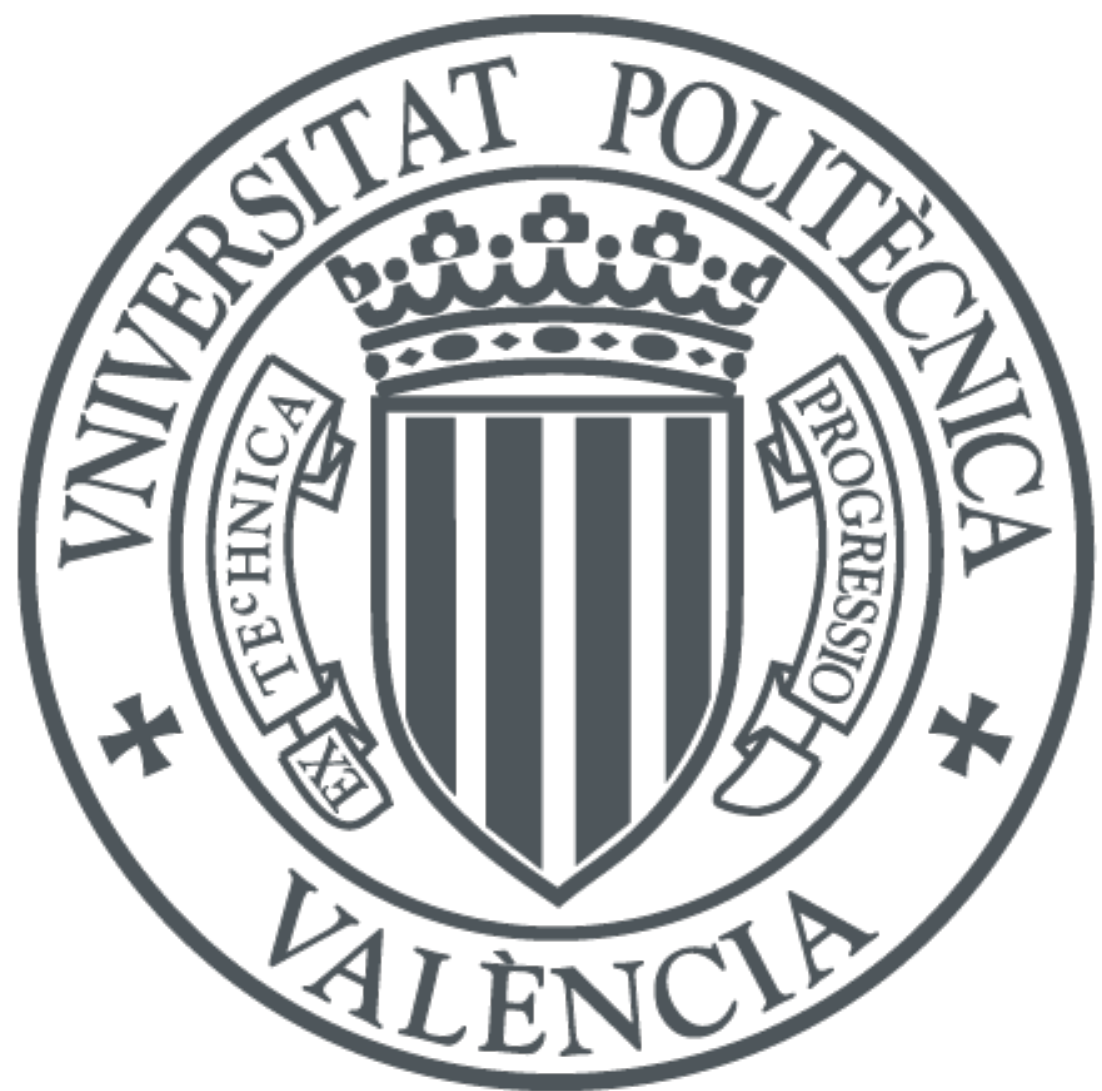

The final publication is available at

http://dx.doi.org/10.1111/str.12067

Copyright WILEY-BLACKWELL

Additional Information 


\title{
Bond of reinforcement in concrete applied to concrete quality control: the Bottle Bond Test
}

Emili García-Taengua*, José-R. Martí-Vargas, Pedro Serna-Ros

ICITECH - Institute of Concrete Science and Technology

Universitat Politècnica de València

Camí de Vera, s/n - 46022 Valencia (Spain)

e-mail address: emgartae@upv.es, jrmarti@cst.upv.es, pserna@cst.upv.es

*Corresponding author:

Tel. +34 686305572, emgartae@upv.es (Emili García-Taengua)

\begin{abstract}
This paper presents the results of an experimental research dealing with bond strength as a parameter for concrete quality control. To this end, a low-cost testing technique has been developed: the Bottle Bond Test (BBT). Specimens for the BBT are produced by casting concrete into empty plastic bottles (used as moulds) with a reinforcing bar longitudinally centered. The result is a bottle-shaped concrete specimen with an embedded rebar which is pulled out to determine bond strength. Different parameters related to this test setup modify bond strength: their effect has been analyzed. An equation to relate the obtained bond strength values to concrete compressive strength is presented. This equation has been validated with real production data from a readymix concrete plant. Its accuracy and therefore the feasibility of BBT for concrete quality control have been verified. Therefore, the BBT can be an alternative to conventional concrete quality based on uniaxial compression tests.
\end{abstract}

\section{Keywords}

test; concrete; bond; compressive strength; quality control. 


\section{Introduction}

Quality control of concrete production applies to a variety of properties of concrete, in both fresh and hardened states. It is of capital importance to assure that the different batches produced are in agreement with the requirements of strength and other properties [1]. Throughout this paper quality control will exclusively refer to concrete bearing capacity. This is monitored on the basis of a standard parameter: concrete compressive strength, most usually evaluated by means of testing cylindrical (or, sometimes, cubic) specimens in uniaxial compression.

As any other parameter used to monitor the quality of any production process, compressive strength values are always scattered but tend to cluster around the mean. The most simple strategy for concrete quality control is based on samples of 3 specimens each. The average value and the standard deviation or coefficient of variation (informing about within-batch variation) are the parameters retained for control and expected to be within some tolerance limits. This is the philosophy which inspires quality control procedures as codified in Eurocode 2 [2] or ACI 318-11 [3], among others.

The aforementioned quality control procedures fall within the general category of Shewhart control charts [4]. In addition to that, there are several other procedures available which constitute more sophisticated approaches to quality control. They have been adapted for the particular case of concrete production, like the CUSUM (Cumulative Sum) control chart [4, 5] or the EWMA (Exponentially Weighted Moving Average) control chart [5]. In spite of the advantages, CUSUM and EWMA control charts are marginally used in concrete production when compared to the most usual strategy of averaging 3-specimens samples per batch, for the sake of simplicity. However, any of these strategies is hardly found at construction sites in 
underdeveloped or developing countries. The inadequate implementation of quality control has been identified as one of the major problems of building industry, for instance in Tanzania [6].

\section{The Bottle Bond Test}

In this context, the Bottle Bond Test (BBT) has been conceived as a low-cost test for quality control of concrete. It is motivated by the belief that transference of technology must rely on realistic criteria and on techniques which are inexpensive and basic [6, 7]. Indeed the BBT is aimed at introducing concrete quality control where it is not usually performed-

The BBT was first devised at Université de Toulose and has been under exploration at several universities in different countries [8, 9]. The BBT is carried out on concrete specimens which are produced using as a mould a plastic bottle after the bottom has been cut and removed, with an embedded reinforcing bar. At the control age, the rebar is pulled out. The bond strength is the test output.

Bond of reinforcement in concrete constitutes the basis of the behaviour and strength of reinforced and prestressed concrete members. Bond strength depends on several factors [10]: concrete strength, concrete cover, reinforcement size and geometry, surface condition, etc. There are several experimental techniques to characterize reinforcement-to-concrete bond behaviour $[11,12]$ : push-in test, pull-out test -the basis of the BBT-, reinforcement end slip and longitudinal concrete strain, among others. These techniques are traditionally used by researchers to study the effects of the aforementioned factors on bond behaviour. Regarding concrete compressive strength, several authors have concluded that bond strength increases 
when concrete strength increases, for both reinforcing bars [13, 14] and prestressing reinforcement $[15,16]$.

Therefore, and as an innovative application, the main objective of this research consists in directly relating the bond strength - obtained by means of the BBT-to concrete compressive strength with an acceptable degree of accuracy, so that the BBT can be regarded as an alternative to uniaxial compression tests on cylindrical or cubic specimens. To this purpose, the rationale behind the BBT is illustrated in Figure 1.

\section{Significance of this research}

The main objective of this research was to develop a test setup and methodology -the BBTwhich can be helpful for concrete production as well as concrete reception. Two particular goals contribute to this general objective. Firstly, to explore how certain variables defining the BBT affect bond strength and its relation to concrete compressive strength evaluated on cylindrical 150x300 mm specimens. And secondly, to assess the feasibility of BBT as a quality control test for concrete compressive strength. This implied: a) evaluating the variability of bond strength values as obtained from the BBT, and b) comparing such variability to that of concrete compressive strength values as obtained by means of cylindrical specimens. Only if such variability is similar in both cases the BBT can be considered a real alternative.

This research constitutes a significant step in developing an alternative test for concrete quality control. The experimental investigation is exhaustive and accurate in both the approach and the analysis methodology. Accurate equations have been obtained to derive compressive strength values from the BBT with an adequate precision. All these aspects make 
the test setup and equations obtained an interesting tool for building and construction companies in developing countries.

With respect to classic compression tests, the BBT presents the main advantage of requiring a reduced and low cost equipment. Furthermore, this paper concludes that the accuracy of both methodologies is reasonably similar when determining concrete compressive strength. However, the BBT is not aimed at replacing the standard compression test, for several reasons: the latter is recommended whenever it is possible, especially for high strength concrete. The BBT is not a substitute but an alternative, mostly useful in areas where standard equipment is unavailable, to be used for concretes within the range it has been developed for: normal strength concretes. All these circumstances frequently converge in many countries, even in the so-called emerging countries. The inadequate implementation of quality control has been identified as one of the major problems of building industry, for instance in Tanzania [6]. In developing countries, the technology to be transferred must rely on realistic criteria, on construction techniques which are simple and basic [6, 7].

\section{Experimental investigation}

\section{Variables considered}

Several parameters are known to affect bond of reinforcement to concrete and therefore bond strength values, namely: rebar diameter, concrete cover, friction between steel and surrounding concrete, and concrete compressive strength. The BBT is conceived to take advantage of the relation between bond strength and concrete compressive strength. However 
other factors related to the way this test is carried out can affect the result. In consequence, it was necessary to explore the effect on bond strength of different variables, in addition to concrete compressive strength. This need justifies the choice of variables which have been considered in this research. They are summarized in Table 1: concrete compressive strength, rebar diameter, state of the rebar surface, and type of bottle.

Three different concrete mix designs have been considered. They cover low- and middlestrength concretes, because the test is thought for low-strength concrete. The research was extended to middle-strength mix designs to know what happens when concrete is better than initially intended. Given the circumstances for which the test is conceived, this research does not consider high compressive strength values, though some previous studies $[4,9,17]$ have considered mixes of up to $100 \mathrm{MPa}$.

No rebar diameters greater than $12 \mathrm{~mm}$ have been considered in order to minimize the risk of splitting of the concrete cover. This favours that the relation between bond strength and concrete compressive strength is clear. Greater rebar diameters would decrease the cover/diameter ratio, which might favour a greater dispersion of bond strength values [10].

The state of rebar surface has been considered as a variable as well. Reinforcing bars can be found in different states of conservation at construction sites. If a rebar is corroded or greasy, friction between steel and concrete is seriously modified and this affects bond strength. This had to be taken into account when relating bond strength values obtained to concrete compressive strength.

The form and size of the bottle used as a mould affects concrete cover and therefore is likely 
to affect bond strength $[10,18]$. This is the reason why different bottles have been used. Types of bottle 1, 2, and 3 correspond to three different bottles for water and soft drinks. Their volume is in all cases between 1.5 and 2.0 litres. Differences between them concern basically shape and surface irregularities, as can be observed in Figure 2.

\section{Experimental program}

As explained in the previous section, 4 variables have been considered, and 3 different values for each one of them have been selected. That makes a total of 81 possible combinations. However, a number of repetitions are needed to analyze the scatter of test results as well. To reduce the number of combinations to be tested and to introduce repetitions, the experimental investigation has been programmed on a statistical basis. The selection of the combinations to be tested has been done by means of orthogonal arrays and derived factorial plans [19]. As a result, only 9 were selected out of the 81 possible combinations. They are listed in Table 2. The statistical criteria followed guarantee that conclusions drawn from the analysis of these combinations is general and reliable.

Repetitions have been introduced to account for the repeatability of the BBT. Three batches were produced for each combination, and three BBT specimens and three cylindrical specimens were cast from each batch. That is to say, 9 BBT specimens and 9 cylindrical specimens were produced and tested for each combination. As a consequence:

- Bond strength and concrete compressive strength values are well defined for all combinations. 
- The scatter of BBT results (bond strength values) can be evaluated and compared to that of concrete compressive strength values obtained by means of testing cylindrical specimens.

- The analysis of results is carried out on a set of highly reliable data, and the quality of conclusions to be drawn is assured.

\section{Materials and mix designs}

Mix designs that have been used are summarized in Table 3. Limestone crushed sand and crushed coarse aggregate have been used, and the cement used has been class CEM I 42.5R (in agreement with [20]) in all cases.

Limestone filler and a high range water reducing admixture have been used as well. Their amounts have been adjusted in each case to have self-compactability conditions. This was necessary to prevent uncontrolled circumstances from affecting test results. Compaction defects have not been considered because it goes beyond the scope of this research.

All reinforcing bars are steel type B500SD (in agreement with [21]).

\section{BBT specimens: geometry and casting}

Figure 3 shows the general scheme of BBT specimens. Different parts can be distinguished along the reinforcing bar: free lengths (outside the bottle), unbounded lengths (by means of sleeves) and embedded length to concrete. A free length of at least $80 \mathrm{~mm}$ of free rebar was kept to facilitate the casting of specimens. A length of at least $250 \mathrm{~mm}$ of free rebar was kept to facilitate the pullout testing of BBT specimens (see next section). The unbounded parts of 
the rebar were necessary for different reasons: a) to limit the embedded length at $100 \mathrm{~mm}$, though other possibilities have been proposed [17]; b) to minimize the effect of compressive reactions on the bottom of the BBT specimen when the rebar is being pulled out (the sleeve was $100 \mathrm{~mm}$ in length); c) and to prevent bond stresses from developing at sections where concrete cover is variable due to the shape of the bottle (this sleeve had a length adjusted to the mould length and shape).

At the section where the tap was, the rebar had to be carefully fastened to prevent fresh concrete from escaping. The rebar had to be relatively centered along the longitudinal axis of the bottle. To do so, adhesive tape was used.

The verticality of the bottle when casting the concrete had to be guaranteed, as well as the position of the rebar. Plastic baskets, wooden blocks, and sand have been used, as shown in Figure 4. Wooden blocks with holes in them were put into plastic baskets to support the rebars. Then the baskets were filled with sand. This way, sand maintains the position of the bottle moulds and the wooden blocks keep the rebar in vertical position. With this simple system, hands are free to cast the concrete into the bottle moulds. However any other methodologies or auxiliary elements can be used as long as they satisfy the aforementioned functions. An alternative would have been not removing completely the bottom part of the plastic bottle and using it for rebar centering [17].

Production of concrete was carried out in all cases following exactly the same sequence and controlling the time for all operations. Components were added to the mixture following this sequence: aggregates, cement, water, and high-range water-reducing admixture. 


\section{Testing of BBT specimens}

In this study, each BBT specimen was placed and tested into a steel frame with a support plate (Figure 5). The reinforcing bar was lined up in the frame passing through a hole in the support plate. The reinforcing bar was pulled out by means of a hydraulic jack coupled at the opposite side of the support plate. A piece of teflon was used to assure correct contact between the BBT specimen and the support plate while pulling the rebar out.

The BBT requires a pressure transducer to control the hydraulic jack. Also a displacement transducer was used to measure the reinforcing bar slip into the concrete. Neither of these measurement devices interfered with the rebar-concrete bond interface.

The applied load/time ratio has been kept between 2 to $4 \mathrm{kN} / \mathrm{min}$ before the peak load is reached. Afterwards slip/time ratio has been kept between 0.4 to $0.6 \mathrm{~mm} / \mathrm{min}$.

The test finishes when the reinforcing bar yields, concrete cover splits, or there is excessive reinforcing bar slippage (typical pullout failure mode).

Based on the uniform bond stress distribution hypothesis which is generally accepted by several codes $[2,3,22]$ and authors $[23,24]$, bond strength values are obtained from equilibrium between the pullout force achieved and the induced bond stresses along the embedded length, as follows:

$$
f_{B B T}=\frac{P}{\pi D L_{e}}
$$

Where:

$f_{B B T} \quad=$ bond strength, averaged along the embedded length 
$P \quad=$ pullout force

$\mathrm{D} \quad=$ nominal diameter of reinforcing bar

$L_{e} \quad=$ embedded length

It is worth noting that the designed BBT specimens are susceptible of being tested in a much simple manner with a reduced test equipment: by means of a single-bar hydraulic jack instead of a steel frame. This can be easily used at construction sites in underdeveloped or developing countries. Performing the BBT in the field is cheaper than standard compression tests. This is mainly because of the following three reasons: common plastic bottles are used as moulds instead of metallic-recoverable moulds, a portable hydraulic jack is required instead of a universal testing machine, and the transport of the equipment required by BBT is easier than the transport of the equipement needed for a standard compression test.

Futhermore, for a systematic application of the BBT, the pullout force could be the parameter retained for quality control instead of the bond strength. This would require extensive experimental studies for every desired reinforcing bar diameter to be systematically used jointly with a constant completely established BBT specimen geometry (mainly embedded length and shape). However, bond strength must be considered when results have been obtained from different embedded lengths and/or reinforcing bar diameters.

\section{Experimental results and discussion}

\section{Experimental results}

BBT specimens and the corresponding companion cylindrical concrete specimens were tested at the age of 28 days after casting. 
Table 4 summarizes experimental results, including: mode of bond failure (the number of specimens per mode is shown), bond strength, and concrete compressive strength. In some of the BBT specimens tested, no bond strength was obtained because the rebar was not pulled out completely in a typical way: either rebar yielding or concrete cover splitting occurred. As illustrated in Figure 6, bond strength is not obtained when the bond failure mode is not pullout. Consequently, bond failure mode will be analyzed (see next section) in addition to bond strength.

\section{Overview of the analysis methodology}

The experimental results have been analyzed in two different stages. The first stage considers results from all specimens and focuses on bond failure mode. The second stage considers only those specimens which bond failure mode was pullout (i.e. rebar yielding and splitting cases are discarded) and focuses on the relation between bond strength and concrete compressive strength.

When bond failure mode is not pullout, no bond strength value is obtained that can be used to estimate concrete compressive strength. However, concrete compressive strength, rebar diameter and concrete cover are involved in the mechanisms determining bond failure mode. Therefore, in these cases some information can still be obtained. Logistic binary regression (LBR hereafter) [25] has been used to analyze how these circumstances determine the mode of failure. 
The results from BBT specimens that experienced neither splitting nor rebar yielding provide bond strength values that can be correlated to concrete compressive strength. This is done by means of multiple linear regression (MLR hereafter) [26]. Variables which do not have a statistically significant effect on bond strength are identified and withdrawn, and a simplified, accurate predictive equation is obtained.

\section{First analysis: variables determining mode of failure}

LBR [25] has been used to relate the probability $(p)$ that a specimen experiences rebar yielding to the variables considered (concrete compressive strength, rebar diameter, state of rebar surface, type of bottle). Splitting has not been analyzed because it has occurred only once (see Table 4): any analysis would have concluded that splitting is expected to occur in only that case, which is unlikely.

LBR is concerned with fitting a predictive equation for $p$, i.e. the probability of rebar yielding. Concrete cover/diameter ratio $(C / D)$ is well known to determine bond failure mode [10]. Therefore, it can be assumed that $p$ is mainly determined by $C / D$. At the same time, it is assumed that the effect of C/D can be modified by the other variables considered: this is represented by a function symbolized as $\Psi$. In consequence, the following equation is proposed:

$$
\frac{p}{1-p}=\exp \left(\Psi_{0}+\Psi \cdot \frac{C}{D}\right)
$$

Considering that the type of bottle determines differences regarding concrete cover, an equivalent formulation for $C / D$ is assumed, as follows: 
$\frac{C}{D}=\left(C_{1}+C_{2} B_{2}+C_{3} B_{3}\right) \cdot \frac{1}{D}$

where $D$ is the rebar diameter (in mm); $C_{1}, C_{2}$, and $C_{3}$ are coefficients to be estimated; $B_{2}$ and $B_{3}$ are boolean variables related to the type of bottle: $B_{2}$ is 1 when the bottle is type 2 , and 0 otherwise; and $B_{3}$ is 1 when the bottle is type 3 , and 0 otherwise.

The function $\Psi$ which modifies the effect of $C / D$ is defined in terms of the other variables as follows:

$\Psi=\psi_{1} f_{c}+\psi_{2} R+\psi_{3} G$

where $\psi_{1}, \psi_{2}$, and $\psi_{3}$ are coefficients to be estimated; $f_{c}$ is concrete compressive strength (in $\mathrm{MPa}) ; R$ is a variable which equals 1 when the rebar is corroded, otherwise it equals 0 ; and $G$ is a variable which equals 1 when the rebar is greasy, otherwise it equals 0 .

All the aforementioned coefficients have been estimated by fitting the logistic model proposed (Eqs. (2-4)) to the observed frequency values. After that, the model has been simplified by stepwise regression [26] to discard variables which effects are not statistically significant. This process has produced the following equation, which predicts the probability of rebar yielding:

$\frac{p}{1-p}=\exp \left(-10.37+\frac{3.14 f_{C}-52.56 G}{D}\right)$

Differences between the types of bottles considered have not been detected to be statistically significant. This confirms that any soft drink or water bottle with a volume between 1.5 and 2.0 litres can be used for the BBT, regardless of the shape. 
Rebar diameter proves to significantly affect the probability of rebar yielding. Figure 7 shows this probability vs rebar diameter for three different values of concrete compressive strength (not greasy rebar). The choice of what rebar diameter is more convenient to perform the test can be reasoned on the basis of Figure 7:

- If 8-mm rebars are used and rebar yielding occurs, concrete compressive strength is at least $25 \mathrm{MPa}$.

- Performing the test with 10 -mm rebars implies that, if yielding occurs, a concrete compressive strength of $35 \mathrm{MPa}$ can be presumed, though this is going to be false in $35 \%(0.35=1-0.65)$ of cases.

- Choosing 12-mm rebars has this advantage: rebar yielding is rather unlikely and theoretically the frequency of unclear cases is no more than $20 \%$. However, the only case where splitting has occurred involves a 12-mm rebar (see Table 2 and Table 4), and therefore a diameter of $12 \mathrm{~mm}$ might not be a good choice.

As a consequence, performing the BBT with 10-mm rebars seems to be the best option. Conservative criteria need to be defined for those control cases where yielding occurs, in order to have a confidence level greater than $65 \%$.

Besides rebar diameter, the state of its surface proves relevant as well. Using a corroded rebar does not make any difference, but using a greasy one does. Figure 8, when compared to Figure 7, shows that the situation is different when a greasy rebar is used. Rebar yielding is unlikely to occur under such circumstances: considering only commercial diameters, the probability of rebar yielding is never higher than 0.05 . As a consequence, using greasy rebars 
may be an alternative to aim at a better classification capacity of the test, though this should be confirmed by further research.

\section{Second analysis: estimation of concrete compressive strength from the BBT}

When no rebar yielding occurs, bond strength $f_{B B T}$ is the outcome of the BBT. It is assumed to be directly related to concrete compressive strength $f_{c}$ (obtained from cylindrical specimens). Therefore a model for $f_{B B T}$ which follows Eq. (6) has to be found:

$$
f_{B B T}=\Gamma \cdot f_{c}
$$

where $\Gamma$ is a function representing the contribution of other circumstances different than $f_{c}$, which are the other variables considered: rebar diameter, state of rebar surface and type of bottle. In this way: the relation between $f_{B B T}$ and $f_{c}$ is assumed to be affected by other variables depending on the test setup.

Function $\Gamma$ must take into account both the state of the rebar and its confinement. It is therefore defined as follows:

$$
\Gamma=\gamma_{1}+\gamma_{2} R+\gamma_{3} G+\frac{C}{D}
$$

where $R, G$ are variables related to the state of the rebar used as previously defined; and $\gamma_{1}, \gamma_{2}$, and $\gamma_{3}$ are coefficients to be estimated.

As explained in the previous section, $C / D$ depends on the type of bottle (see Eq. (3)). Therefore Eq. (7) can be rewritten as follows:

$\Gamma=\gamma_{1}+\gamma_{2} R+\gamma_{3} G+\frac{C_{1}+C_{2} B_{2}+C_{3} B_{3}}{D}$ 
Coefficients in Eq. (8) are estimated by fitting this model to experimental results by least squares (MLR). Stepwise regression [26] is used to recalculate them once statistically unsignificant variables are withdrawn. The values obtained for the coefficients in Eq. (8) are: $C_{2}=C_{3}=0 ; \gamma_{1}=0.606, \gamma_{2}=0.072$, and $\gamma_{3}=-0.132$. Then Eq. (8) is simplified and rewritten as follows:

$$
\frac{f_{B B T}}{f_{c}}=K-\frac{2.278}{D}
$$

where $D$ is the rebar diameter (in $\mathrm{mm}$ ) and $K$ is a friction parameter whose value depends on the state of the rebar used: 0.606 for clean rebar, 0.474 for greasy rebar, and 0.678 for corroded rebar. It is worth noting that coefficient $K$ in Eq. (9) reflects that rusty rebars are better bonded to concrete than clean rebars, and clean rebars are better bonded than greasy rebars: $0.678>0.606>0.474$. That is: the better the anchorage, the higher $f_{B B T}$ is going to be for a certain $f_{c}$.

The fitted equation is highly accurate, presenting a R-squared value of $90.12 \%$. Therefore, Eq. (9) represents a very simple and precise way to determine the ratio between the bond strength obtained in the BBT $\left(f_{B B T}\right)$ and concrete compressive strength $\left(f_{c}\right)$. However, the aforementioned R-squared value informs about how accurately $f_{\mathrm{BBT}} / f_{c}$ is predicted, but the really interesting thing is to find out how accurately $f_{c}$ values are predicted from $f_{B B T}$ values.

If Eq. (9) is applied to the dataset this analysis is based upon, pairs of predicted $f_{c}$ vs observed $f_{c}$ are obtained. The goodness of fit between predicted and observed $f_{c}$ values measures the predictive capacity of Eq. (9). These pairs of values are shown in Figure 9, together with the exact equivalence line and the limits of the 95\%-confidence band. The R-squared is $73.66 \%$, which stands for a direct measure of the accuracy of Eq. (9) as a correlation tool to be used together with the BBT for concrete quality control. This R-squared value proves that the BBT 
together with Eq. (9) is as reliable as testing cylindrical specimens under uniaxial compression. This is further discussed in the following paragraph in terms of coefficient of variation.

The average of the observed $f_{c}$ values is $33.6 \mathrm{MPa}$, and the average of the predicted $f_{c}$ values is 37.9 MPa. Therefore, the average distance between predicted and observed $f_{c}$ values is 4.3 MPa. In consequence, the relative standard deviation of predicted $f_{c}$ values with respect to observed values is $4.3 / 33.6=12.7 \%$. On the other hand, values up to $11 \%$ for the withinbatch coefficient of variation of concrete compressive strength are considered satisfactory for most situations [27]. Therefore, comparing $12.7 \%$ to $11 \%$, it is concluded the BBT together with Eq. (9) constitute as accurate a tool for quality control as testing cylindrical specimens.

\section{Validation with real production data}

In order to validate Eqs. (5) and (9), additional results corresponding to specimens which have not been used to obtain these equations have been used. These results have been obtained from a total of 54 BBT specimens and 54 cylindrical specimens, corresponding to 9 different batches of concrete (6 BBT specimens and 6 cylindrical specimens per batch) produced in a readymix concrete plant. All these BBT specimens have been produced using type 2 bottles and 12-mm rebars with clean surface. Though the best choice for extensive application is 10mm rebars, as previously justified, 12-mm rebars were used to have rebar yielding cases as well.

Rebar yielding occurred in 4 out of these 9 batches, and therefore the accuracy of Eq. (5) to predict the probability of rebar yielding could also be verified with these new data. 
Results are shown in Table 5 organized under the headings "Observed" and "Predicted", including predicted rebar yielding probabilities according to Eq. (5). This equation proves to predict pretty well what really happens in each case. Predicted probabilities higher than 0.5 match rebar yielding cases. On the other hand, predicted probabilities less than 0.5 indicate that no rebar yielding occurs, and this is true in all cases except one. Therefore, Eq. (5) proves to be correct in 8 out of 9 cases.

Figure 10 shows observed $f_{c}$ values vs predicted $f_{c}$ values, calculated by means of Eq. (9). Three lines are shown: a central one which corresponds to the exact equivalence (slope=1, no intercept), and two other lines which correspond to the limits of the 95\%-confidence band of the prediction. The width of such confidence band is 4 times the residual standard error (RSE=0.97 MPa) with respect to the exact equivalence line [26, 28]. However, values in the validation dataset have been averaged from 6 values each $\left(\mathrm{RSE}_{(6)}\right.$ in readymix concrete plant), while the predictive equation assumes sets of 3 values $\left(\mathrm{RSE}_{(3)}\right.$ in the experimental program of this research). This is the reason why one out of the 5 points falls outside the $95 \%$-confidence band: because that is not the appropriate 95\%-confidence band to take into account.

That can be easily worked out. On a combinatory basis, each 6-specimen sample is equivalent to 20 3-specimen subsamples. If all these subsamples are considered, a virtually expanded dataset is obtained, which consists of 180 3-specimen samples. Then sample size in the validation dataset is the same one assumed for Eq. (9). And it is on this virtually expanded dataset that the 95\%-confidence interval must be calculated. Figure 11 shows predicted vs observed average values for concrete compressive strength, the exact equivalence line, and the limits of the 95\%-confidence band. In this case, the estimated RSE with respect to the 
exact equivalence line is directly $\mathrm{RSE}_{(3)}$ and its value is $1.6 \mathrm{MPa}$. It is observed that some points still fall outside the 95\%-confidence band in Figure 11: this is due to the fact that $5 \%$ of all points are necessarily not contained within such limits, by definition.

Considering that the average of observed values for concrete compressive strength is 35.3 MPa, the relative standard deviation of predicted $f_{c}$ values around observed $f_{c}$ values is $1.6 / 35.3=4.5 \%$. This is clearly acceptable for a test aimed at concrete quality control, and validates the BBT as an alternative to testing cylindrical specimens under uniaxial compression. The discrepancy with the value obtained with data from the experimental program (12.7\%) has the following explanation: a variety of different situations regarding rebar diameter, rebar surface and type of bottle were considered in the experimental program; however, in the validation dataset, such sources of variability have been removed by considering only 12-mm clean rebars.

\section{Summary and conclusions}

The Bottle Bond Test (BBT) relates bond strength to concrete compressive strength and has been developed as a simple alternative to conventional concrete quality control when the access to control laboratories is complicated because of the lack of appropriate means. Based on the experimental results and the outcomes of their validation with external data, the following conclusions are drawn:

1. A particular methodology for the BBT has been proposed concerning general dimensions of specimens, mounting of bottle moulds, positioning of rebars, and casting of concrete. This methodology is a flexible one, because it admits several variations depending on the circumstances and means available as long as the main 
features are observed: centering of the rebar, verticality of the bottle mould when casting, and an adequate compaction of fresh concrete right after casting. The flexibility and low cost of this methodology makes the BBT an interesting option for quality control of concrete in developing countries.

2. A series of tests have been performed to study the effect that rebar diameter, the state of its surface (clean, corroded, or greasy) and the use of different bottles as moulds have on test results when low- and middle-strength concretes are concerned.

3. No differences have been found among the three different types of bottle moulds considered in this research. This constitutes an important finding, because it means that the test can be performed with any type of bottle mould available as long as their volume is between 1.5 and 2.0 litres. Therefore this is one more feature which makes the BBT very accessible.

4. Rebar yielding prevents any relation from being established to concrete compressive strength. However, it has been shown that rebar yielding is a signal that a minimum strength value has been achieved. Therefore, even when rebar yielding occurs, the BBT informs that a minimum concrete compressive strength value is guaranteed.

5. An equation to predict the probability of rebar yielding has been obtained. It has been found that it is affected by rebar diameter and the state of the rebar surface. This equation, combined with the recommendation of testing 3-specimens samples, makes it possible to guarantee a minimum acceptable value of concrete compressive strength when rebar yielding occurs.

6. An equation which accurately relates bond strength as obtained from the BBT to concrete compressive strength has been obtained. In the cases when no rebar yielding occurs, this equation provides an accurate evaluation of concrete compressive strength. 
7. The relationship between $f_{B B T}$ and $f_{c}$ has proved that BBT is as reliable a tool for concrete's quality control as testing cylindrical specimens. It has been proved that the capacity of BBT is quite close to that of the standard uniaxial compression test: the BBT is therefore an alternative to cylindrical specimen with no loss of certitude.

\section{Acknowledgments}

The authors of this work wish to thank both the Research Bureau of the Spanish Ministry of Science and Innovation and the "Plan E" program for the funding of the project "BIA 2009$12722 "$, this research being a part thereof. 


\section{References}

[1] Cattaneo, S., \& Mola, F. (2012). Assessing the Quality Control of Self-Consolidating Concrete Properties. ASCE Journal of Construction Engineering and Management 128(2):197-205.

[2] Comité Européen de Normalisation (CEN). (2004). “Eurocode 2: Design of concrete structures - Part 1-1: General rules and rules for buildings.” European standard EN 1992-11:2004:E, Comité Européen de Normalisation, Brussels, Belgium.

[3] American Concrete Institute (2011) ACI 318-11. ACI Committee 318: Building Code Requirements for Reinforced Concrete. American Concrete Institute, Farmington Hills, MI. [4] Chung, H. W. (1993). Control of Concrete Quality Through Statistics. Concrete International 15(5):38-43.

[5] Laungrungrong, B., Mobasher, B., Montgomery, D., \& Borror, C. M. (2010). Hybrid Control Charts for Active Control and Monitoring of Concrete Strength. ASCE Journal of Materials in Civil Engineering 22(1):77-87.

[6] Mwamila, B.L.M, \& Karumuna, B.L. (1999). Semi-prefabrication concrete techniques in developing countries. Building Research \& Information 27(3):165-182.

[7] Kumaraswamy, M.M., \& Shrestha, G.B. (2002) Targeting 'technology exchange' for faster organizational and industry development. Building Research \& Information 30(3):183-195. [8] Lorrain, M., \& Barbosa, M. (2008). Controle de qualidade dos concretos estruturais: ensaio de aderência aço-concreto. Revista Concreto, Jul.-Aug. 2008, pp. 55-60.

[9] Lorrain, M., Pinto-Barbosa, M., \& Arnaud, M. (2010). Bond test and on-site structural concrete quality control. Proceedings of the 3rd fib International Congress, Washington. [10] International Federation for Structural Concrete (2000) Bond of reinforcement in concrete. State of the art report. FIB Bulletin nº10. Lausanne. 
[11] Martí-Vargas, J.R., Arbeláez, C.A., Serna-Ros, P., Fernández-Prada, M.A. and Miguel-

Sosa, P.F. (2006) Transfer and development lengths of concentrically prestressed concrete. PCI J. 51(5), 74-85.

[12] Martí-Vargas, J.R., Caro, L.A. and Serna, P. (2013) Experimental technique for measuring the long-term transfer length in prestressed concrete. Strain 49, 125-134. [13] Lorrain M, Khelafi H. Contribution a l'etude de l'endommagement de la liaison armature-beton de haute performance. Mater Struct 1989;22:127-138.

[14] Yerlici, V.A., Ozturan, T. (2000) Factors Affecting Anchorage Bond Strength in High Performance Concrete. ACI Struct. J. 97(3):499-507.

[15] Martí-Vargas, J.R., Serna, P., Navarro-Gregori, J. and Bonet, J.L. (2012) Effects of concrete composition on transmission length of prestressing strands. Constr. Build. Mater. 27(1), 350-356.

[16] Martí-Vargas, J.R., Serna, P., Navarro-Gregori, J. and Pallarés, L. (2012) Bond of 13 mm prestressing steel strands in pretensioned concrete members. Eng. Struct. 41, 403-412. [17] Do Vale Silva, B., Pinto Barbosa, M., Pinto da Silva, L., Lorrain, M., \& Dal Bosco, V.I. (2011). Correlaçao entre a tensao última de aderencia e a resistencia do concreto usando ensaio "APULOT": avaliaçao do efeito de variaçao do cobrimento do concreto ao redor da barra de aço. Anais do $53^{\circ}$ Congresso Brasileiro do Concreto IBRACON CBC2011, Florianópolis.

[18] García-Taengua, E., Martí-Vargas, J. R., \& Serna-Ros, P. (2011). Statistical Approach to Effect of Factors Involved in Bond Performance of Steel Fiber-Reinforced Concrete. ACI Structural Journal 108(4):461-468.

[19] Montgomery, D. (2009). Design and Analysis of Experiments. John Wiley \& Sons Publisher, New York. 
[20] European Committee for Standardisation (2011). EN 197-1:2011. Cement-Part 1:

Composition, specifications and conformity criteria for common cements.

[21] European Committee for Standardisation (2005). EN 10080:2005. Steel for the reinforcement of concrete - Weldable reinforcing steel - General.

[22] Martí-Vargas JR, Hale WM. Predicting strand transfer length in pretensioned concrete:

Eurocode versus North American practice, ASCE J Bridge Eng 2013.

http://dx.doi.org/10.1061/(ASCE)BE.1943-5592.0000456 .

[23] Martí-Vargas, J.R., Arbeláez, C.A., Serna-Ros, P. and Castro-Bugallo, C. (2007)

Reliability of transfer length estimation from strand end slip. ACI Struct. J. 104(4), 487-494.

[24] Martí-Vargas JR, Serna P, WM Hale. Strand bond performance in prestressed concrete accounting for bond slip. Eng Struct 2013;51:236-244.

[25] Kleinbaum, D., \& Klein, M. (2010). Logistic Regression: A Self-Learning Text. Springer Science, New York, 2010.

[26] Hair, J., Black, W., Babin, B., \& Anderson, R. (2010). Multivariate Data Analysis.

Prentice Hall, Upper Saddle River, New Jersey.

[27] American Concrete Institute, Committee 214 (2011). Report 214R-11. Guide to

Evaluation of Strength Test Results of Concrete. Farmington Hills, MI.

[28] Box G.P. (2009). Statistics for Experimenters: Design, Innovation and Discovery. WileyBlackwell, John Wiley \& Sons Publisher, New York. 


\section{List of Tables:}

Table 1: Variables considered.

Table 2: Combinations tested.

Table 3: Mix designs used.

Table 4: Experimental investigation: summary of test results.

Table 5: Validation with real production data: summary of test results.

\section{List of Figures:}

Figure 1: The Bottle Bond Test (BBT) and its relation to concrete compressive strength.

Figure 2: Types of bottle considered.

Figure 3: General scheme of a BBT specimen.

Figure 4: Bottle moulds and rebars prepared and right before casting.

Figure 5: BBT carried out on one BBT specimen.

Figure 6: Bond failure modes.

Figure 7: Probability of rebar yielding vs rebar diameter for different concrete compressive strength values (rebar not greasy).

Figure 8: Probability of rebar yielding vs rebar diameter for different concrete compressive strength values (greasy rebar).

Figure 9: Predicted vs observed values for concrete compressive strength.

Figure 10: Validation with data from a readymix concrete plant (real, as-observed dataset).

Figure 11: Validation with data from a readymix concrete plant (virtually expanded dataset). 
Table 1: Variables considered.

\begin{tabular}{ll}
\hline \hline \multicolumn{1}{c}{ Variable } & \multicolumn{1}{c}{ Values } \\
\hline Mix design $-f_{c}$ & $\mathrm{~A}-56.5 \mathrm{MPa}$ \\
& $\mathrm{B}-39.8 \mathrm{MPa}$ \\
$\mathrm{C}-28.2 \mathrm{MPa}$ \\
\hline Rebar diameter & $8 \mathrm{~mm}$ \\
& $10 \mathrm{~mm}$ \\
& $12 \mathrm{~mm}$ \\
\hline & Clean \\
Rebar surface & Corroded \\
& Greasy \\
\hline Bottle mould type & 2 \\
\hline \hline
\end{tabular}


Table 2: Combinations tested.

\begin{tabular}{ccccc}
\hline \hline Id & $\begin{array}{c}\text { Mix } \\
\text { design }\end{array}$ & $\begin{array}{c}\text { Rebar diameter } \\
\text { mm }\end{array}$ & $\begin{array}{c}\text { Rebar } \\
\text { surface }\end{array}$ & $\begin{array}{c}\text { Bottle } \\
\text { type }\end{array}$ \\
\hline \hline 1 & A & 8 & Clean & 1 \\
\hline 2 & A & 10 & Greasy & 2 \\
\hline 3 & A & 12 & Corroded & 3 \\
\hline 4 & B & 8 & Corroded & 2 \\
\hline 5 & B & 10 & Clean & 3 \\
\hline 6 & B & 12 & Greasy & 1 \\
\hline 7 & C & 8 & Greasy & 3 \\
\hline 8 & C & 10 & Corroded & 1 \\
\hline 9 & C & 12 & Clean & 2 \\
\hline \hline
\end{tabular}


Table 3: Mix designs used.

\begin{tabular}{lccc}
\hline \hline $\mathrm{kg} / \mathrm{m}^{3}$ & $\mathrm{~A}$ & $\mathrm{~B}$ & $\mathrm{C}$ \\
\hline \hline Cement & 420 & 325 & 325 \\
\hline Total water & 194 & 195 & 227 \\
\hline $\begin{array}{l}\text { Coarse aggregate } \\
(7 / 12+12 / 20)\end{array}$ & $721+0$ & $528+348$ & $503+332$ \\
\hline Sand & 957 & 977 & 933 \\
\hline Limestone filler & 72 & 55 & 55 \\
\hline Superplasticiser & 8.8 & 2.75 & 1.33 \\
\hline \hline
\end{tabular}


Table 4: Experimental investigation: summary of test results.

\begin{tabular}{cccccc}
\hline \multicolumn{5}{c}{$\begin{array}{c}\text { Mode of failure } \\
\text { Id }\end{array}$} & \multicolumn{2}{c}{ (number of specs. each) } & & \\
\cline { 2 - 5 } & Pullout & Rebar & Cover \\
yield & Bond strength & Compressive \\
splitting & $f_{B B T}$, MPa & strength $f_{c}$, MPa \\
\hline \hline 1 & 0 & 9 & 0 & - & 55.4 \\
\hline 2 & 1 & 8 & 0 & 12.4 & 56.8 \\
\hline 3 & 0 & 1 & 8 & - & 57.4 \\
\hline 4 & 0 & 9 & 0 & - & 39.8 \\
\hline 5 & 1 & 8 & 0 & 13.8 & 41.0 \\
\hline 6 & 9 & 0 & 0 & 11.4 & 40.4 \\
\hline 7 & 9 & 0 & 0 & 5.6 & 28.3 \\
\hline 8 & 8 & 1 & 0 & 12.6 & 28.1 \\
\hline 9 & 8 & 1 & 0 & 12.2 & 28.3 \\
\hline \hline
\end{tabular}


Table 5: Validation with real production data: summary of test results.

\begin{tabular}{ccc|ccc|cc}
\hline \hline \multicolumn{3}{c|}{ Mode of failure } & \multicolumn{3}{c|}{ Observed } & \multicolumn{2}{c}{ Predicted } \\
\hline \hline \multirow{2}{*}{$\begin{array}{c}\text { Rebarlout } \\
\text { yield }\end{array}$} & Splitting & yrob. of & $f_{c}$ & $f_{B B T}$ & Prob. of \\
yPa & yielding & $f_{c}$ \\
\hline \hline 6 & 0 & 0 & 0.0 & 38.8 & 15.0 & 0.446 & 36.0 \\
\hline 6 & 0 & 0 & 0.0 & 34.8 & 14.0 & 0.220 & 33.6 \\
\hline 6 & 0 & 0 & 0.0 & 33.9 & 13.6 & 0.184 & 32.7 \\
\hline 0 & 6 & 0 & 1.0 & 44.5 & - & 0.781 & - \\
\hline 0 & 5 & 1 & 0.8 & 33.8 & - & 0.179 & - \\
\hline 0 & 6 & 0 & 1.0 & 45.2 & - & 0.811 & - \\
\hline 5 & 6 & 0 & 1.0 & 42.8 & - & 0.696 & - \\
\hline 3 & 0 & 1 & 0.0 & 34.7 & 14.4 & 0.216 & 34.6 \\
\hline \hline
\end{tabular}

